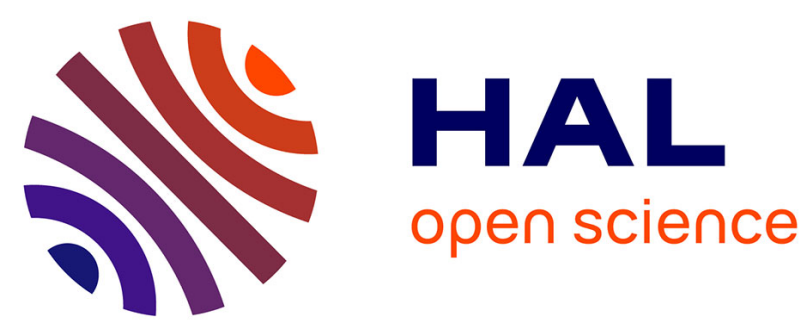

\title{
Local micro-photoreflectance spectroscopy measurements on type II InGaAlAs/GaAsSb/InP heterojunction bipolar transistor: Correlation with electrical characteristics
}

H. Chouaib, C. Bru-Chevallier

\section{To cite this version:}

H. Chouaib, C. Bru-Chevallier. Local micro-photoreflectance spectroscopy measurements on type II InGaAlAs/GaAsSb/InP heterojunction bipolar transistor: Correlation with electrical characteristics. Applied Physics Letters, 2012, 100 (17), 10.1063/1.4705408 . hal-01901728

\section{HAL Id: hal-01901728 \\ https://hal.science/hal-01901728}

Submitted on 9 Jan 2019

HAL is a multi-disciplinary open access archive for the deposit and dissemination of scientific research documents, whether they are published or not. The documents may come from teaching and research institutions in France or abroad, or from public or private research centers.
L'archive ouverte pluridisciplinaire HAL, est destinée au dépôt et à la diffusion de documents scientifiques de niveau recherche, publiés ou non, émanant des établissements d'enseignement et de recherche français ou étrangers, des laboratoires publics ou privés. 


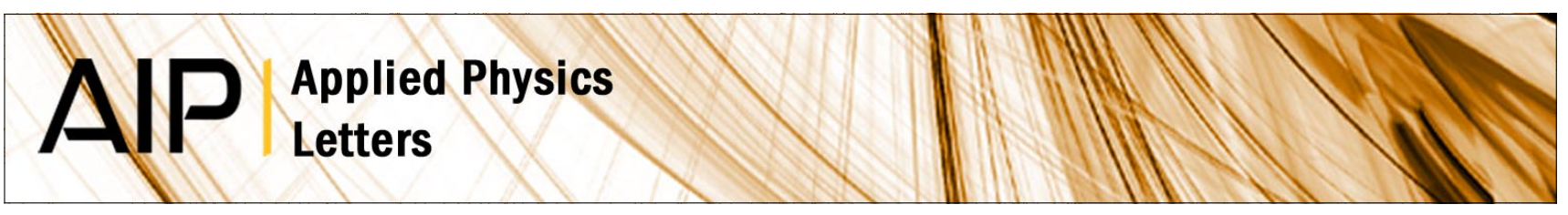

\section{Local micro-photoreflectance spectroscopy measurements on type II InGaAIAs/GaAsSb/InP heterojunction bipolar transistor: Correlation with electrical characteristics}

H. Chouaib and C. Bru-Chevallier

Citation: Appl. Phys. Lett. 100, 172102 (2012); doi: 10.1063/1.4705408

View online: http://dx.doi.org/10.1063/1.4705408

View Table of Contents: http://apl.aip.org/resource/1/APPLAB/v100/i17

Published by the American Institute of Physics.

\section{Related Articles}

Modeling of current gain compression in common emitter mode of a transistor laser above threshold base current J. Appl. Phys. 111, 083103 (2012)

A 10 tesla table-top controlled waveform magnet

Rev. Sci. Instrum. 83, 045103 (2012)

Physical origins of nonlinearity in InP double heterojunction bipolar transistors

Appl. Phys. Lett. 100, 113508 (2012)

Chalcogenide glass surface passivation of a GaAs bipolar transistor for unique avalanche terahertz emitters and picosecond switches

Appl. Phys. Lett. 100, 073505 (2012)

Transformation kinetics of an intrinsic bistable defect in damaged silicon

J. Appl. Phys. 111, 023715 (2012)

\section{Additional information on Appl. Phys. Lett.}

Journal Homepage: http://apl.aip.org/

Journal Information: http://apl.aip.org/about/about_the_journal

Top downloads: http://apl.aip.org/features/most_downloaded

Information for Authors: http://apl.aip.org/authors

\section{ADVERTISEMENT}

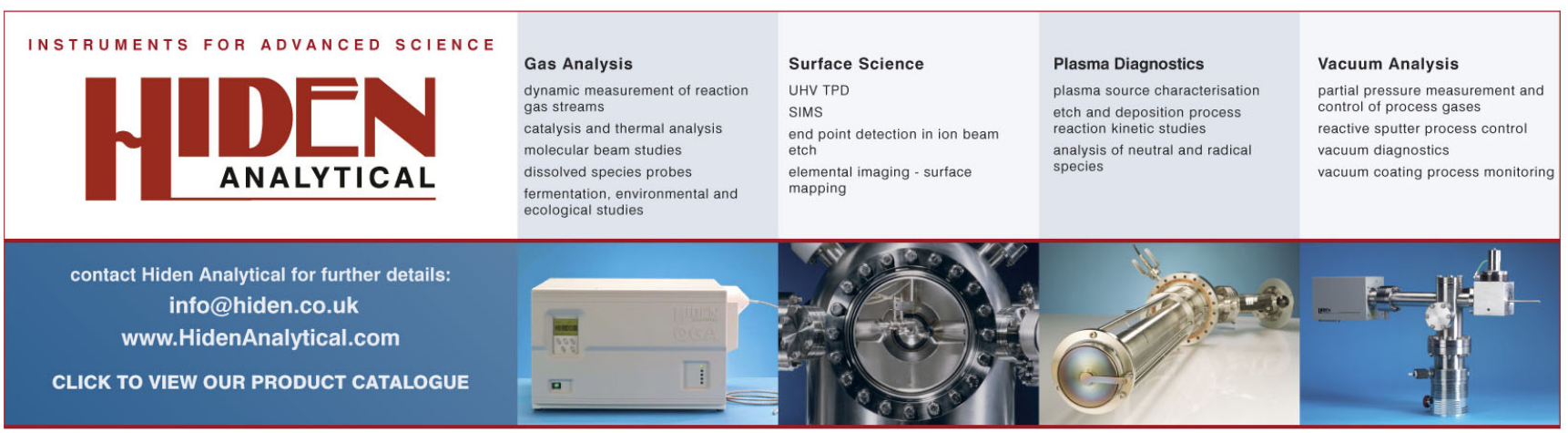




\title{
Local micro-photoreflectance spectroscopy measurements on type II InGaAIAs/GaAsSb/InP heterojunction bipolar transistor: Correlation with electrical characteristics
}

\author{
H. Chouaib ${ }^{\text {a) }}$ and C. Bru-Chevallier \\ Institut des Nanotechnologies de Lyon (INL)-UMR5270-CNRS, Université de Lyon, INSA-Lyon, \\ 69621 Villeurbanne, France
}

(Received 11 February 2012; accepted 4 April 2012; published online 24 April 2012)

\begin{abstract}
Micro-photoreflectance (micro-PR) is performed on patterned type II InGaAlAs/GaAsSb/InP heterojunction bipolar transistor to locally measure the built-in electric fields. The results show that the efficiency of the electric field modulation correlates with the ideality factor extracted from the electrical characteristics (Gummel characteristics). The Franz-Keldysh oscillations (FKO) completely disappear at the emitter/base heterojunction on devices with high ideality factor (nearly 2), whereas typical FKO spectra are seen on samples with ideality factor $\sim 1$. Such behavior is attributed to the type II recombination across the InGaAlAs/GaAsSb interface which can reduce the photovoltage effect. Prior to the micro-PR experiments, photoluminescence is performed to demonstrate that the InGaAlAs/GaAsSb interface nature is of type II as well as to estimate the band offset discontinuity $\Delta \mathrm{E}_{\mathrm{C}}$. (C) 2012 American Institute of Physics. [http://dx.doi.org/10.1063/1.4705408]
\end{abstract}

Heterojunction bipolar transistors (HBT) grown on InP substrates have attracted considerable attention due to their applications for the next generations of integrated circuits operating at very high speed exceeding $100 \mathrm{Gbits} / \mathrm{s}$. Traditionally, GaInAs was used for InP based HBTs which have demonstrated high-speed characteristics. ${ }^{1,2}$ However, the $\mathrm{InP} / \mathrm{GaInAs}$ heterostructure has a type I conduction band alignment causing a current blocking at the base-collector (B/C) heterojunction. In an effort to overcome this limitation and suppress the collector current blocking of the InP/ GaInAs HBT, methods of composition and doping graded layers have been suggested and implemented. ${ }^{2,3}$ Such design for a graded structure, although their success, has made the epitaxial layer growth much more complex. As an alternative to the GaInAs, the ternary GaAsSb is believed to provide a solution to the $\mathrm{B} / \mathrm{C}$ current blocking since its band offset with InP layer is of type II, and electrons are therefore ballistically injected into the collector. ${ }^{4,5}$ Furthermore, due to the large valence band discontinuity, the hole blocking process at the collector and the emitter is stronger than the GaInAs based devices one. Excellent performances were reported using an $\mathrm{InP} / \mathrm{GaAsSb} / \mathrm{InP}$ HBT devices, particularly with maximum cutoff frequency $\mathrm{Ft}$ and maximum oscillation frequency Fmax surpassing $300 \mathrm{GHz} .{ }^{6,7}$ However, while the negative conduction band discontinuity $\left(\Delta \mathrm{E}_{\mathrm{C}}\right)$ for the $\mathrm{GaAsSb}$ base to the InP collector is considered a major advantageous factor to the HBT performance, it is a disadvantage from the InP emitter side since a negative $\Delta \mathrm{E}_{\mathrm{C}}$ at the InP emitter/base (E/B) GaAsSb is a barrier against the electrons injected into the base. Therefore, an ideal case would be to have a type II B/C interface and type I E/B interface. A heterostructure design lead, promising a positive $\Delta \mathrm{E}_{\mathrm{C}}$ at the $\mathrm{E} / \mathrm{B}$

\footnotetext{
a) Author to whom correspondence should be addressed. Electronic mail: houssam.chouaib@kla-tencor.com. Present address: KLA-Tencor Corp. 1 Technology Dr., Milpitas, California 95035, USA
}

interface was proposed by Bove et al. ${ }^{8}$ replacing the InP. This material is the quaternary InGaAlAs. While the GaInAs/GaAsSb is of a type II heterostructure, the InAlAs/ $\mathrm{GaAsSb}$ one is of type I. By mixing GaInAs and InAlAs, one can hope getting an InGaAlAs emitter with a positive (type I) conduction band discontinuity as an alternative to $\mathrm{InP}$ for HBT with GaAsSb.

To explore the various physical properties of these structures and the devices based on them, various optical characterization methods are used, in particular the photoluminescence (PL) and photoreflectance (PR $)^{9,10}$ spectroscopy. PL and PR offer the advantage of being nondestructive and contactless methods, they can provide a number of valuable information and are able to measure some critical parameters for the HBT application, like in our case the InGaAlAs bandgap, the InGaAlAs/GaAsSb interface nature (type I or type II), and its band offset discontinuity, or in some other cases the surface Fermi level which provides a guide for predicting the contact resistivity. ${ }^{11-13}$ In addition, room temperature PR spectroscopy has proven a significant ability in the qualification of HBT epitaxial structures. Similar studies have been widely published in the literature. ${ }^{14,15}$ Scientists skilled in the field have generally applied PR by the mean of a standard setup with a mediocre spatial resolution (Millimetric scale). Once the epitaxial wafers have been optically characterized, they are processed afterwards and undergo a number of technological steps where eventual damages or surface states modifications could occur leading to change in the optical response and/or electrical characteristics. Investigators have then compared and correlated both optical and electrical characterizations results although they are separated by series of technological processes. Another reason for performing local measurement on real devices is the micro-loading effect which means the structure size and density effect, such as the local variation in growth rate and composition or thickness non-uniformity etc. As a result, 
micro-photoreflectance (micro-PR) is used to locally characterize real micro-devices, and the emerging optical results are subsequently compared to electrical characteristics performed on the same compound.

In this paper, InGaAlAs layers and InGaAlAs/GaAsSb heterostructures are first optically investigated using PL and PR spectroscopy, in order to determine the InGaAlAs bandgap, the nature of the InGaAlAs/GaAsSb interface (Type I or II), and its band offsets $\Delta \mathrm{E}_{\mathrm{C}}$ and $\Delta \mathrm{E}_{\mathrm{V}}$. These parameters are crucial for the HBT operation as well as its design and modeling. Moreover, the paper also covers the InGaAlAs/GaAsSb/InP HBT devices micro-PR results, showing a correlation between the optical measurement and the electrical characteristics (Gummel characteristics). We shall consider how optical spectroscopy techniques characterize real micro-devices to improve their performances.

The InGaAlAs/GaAsSb layers are grown by molecular beam epitaxy (MBE) on InP substrates. It consists of a $100 \mathrm{~nm}$ InGaAlAs layer grown on a $50 \mathrm{~nm}$ C-doped GaAsSb layer. $\mathrm{Al}$ and $\mathrm{Sb}$ mole fractions for both samples are extracted from x-ray diffraction measurements. We found $25 \% \mathrm{Al}$ for InGaAlAs and $43 \% \mathrm{Sb}$ for GaAsSb layer.

In order to measure the bandgap energy of the InGaAlAs layer, room temperature PR was performed. The corresponding PR spectrum is reported on Figure 1 in the $0.95 \mathrm{eV}-1.2 \mathrm{eV}$ energy range. The spectrum clearly shows two transitions coming from the energy bandgaps of the quaternary layer lattice mismatched to the GaAsSb layer. In case of low electric field regime, PR spectrum is regressed with the third derivative of the dielectric function (TDFF) model. ${ }^{16}$ Therefore, the PR spectrum regression provides two energy transitions at $1.096 \mathrm{eV}$ and $1.128 \mathrm{eV}$ as reported in Table I. For InGaAlAs under tensile strain, the light hole ( $\mathrm{LH})$ valence band is located above the heavy hole $(\mathrm{HH})$ band and therefore the $1.096 \mathrm{eV}$ energy is attributed to the LH bandgap and the $1.128 \mathrm{eV}$ to the $\mathrm{HH}$ bandgap. It is worthnoting to mention that both $\mathrm{HH}$ and $\mathrm{LH}$ transitions exhibit quite similar broadening parameters as shown in Table I. This indicates the reliability of the regression results which are consistent with previous work obtained on III-V

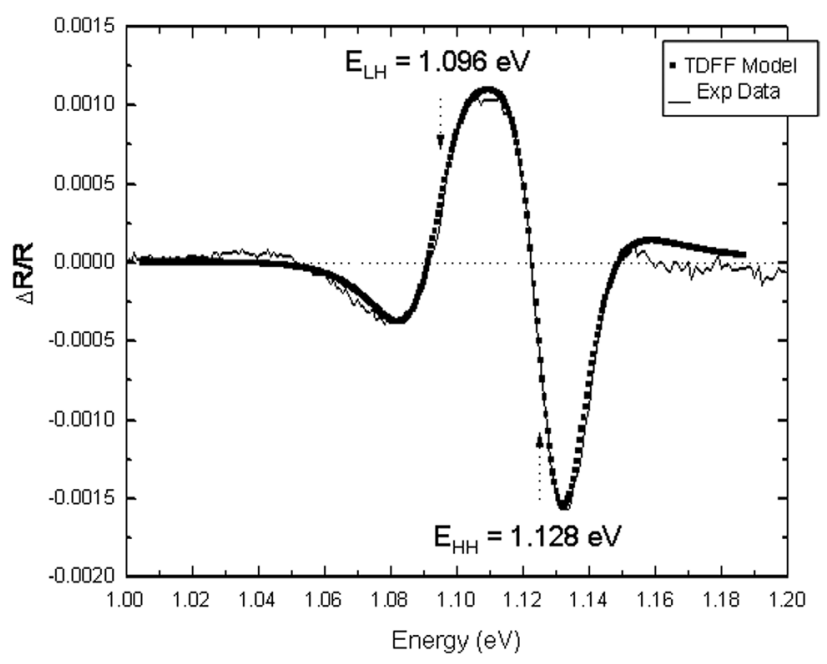

FIG. 1. Room temperature PR spectrum of InGaAlAs layer (25\% Al). Squares are the fit obtained using the third derivative functional form model.
TABLE I. Third derivative functional form model regression results of the InGaAlAs LH and $\mathrm{HH}$ energy transitions at room temperature for $25 \% \mathrm{Al}$.

\begin{tabular}{lcccc}
\hline \hline Transition & Amplitude & $\begin{array}{c}\text { Broadening } \\
(\mathrm{meV})\end{array}$ & $\begin{array}{c}\text { Energy } \\
(\mathrm{eV})\end{array}$ & Phase \\
\hline LH & $(1.02 \pm 0.05) \times 10^{-8}$ & $24 \pm 1$ & $1.096 \pm 0.04$ & $0.39 \pm 0.016$ \\
LH & $(1.4 \pm 0.06) \times 10^{-8}$ & $20 \pm 0.8$ & $1.128 \pm 0.05$ & $3.96 \pm 0.16$ \\
\hline \hline
\end{tabular}

systems. ${ }^{17}$ Additionally, our results confirm that the HH PR amplitude, which is often described as the oscillator strength of the transition is in fact greater than that of the $\mathrm{LH}\left(\mathrm{A}_{\mathrm{HH}} /\right.$ $\left.A_{L H}=1.4\right)$. Similar behaviors are also reported and theoretically analyzed in the literature. ${ }^{18}$

Samples are further studied by PL at $10 \mathrm{~K}$ to determine the nature of the InGaAlAs/GaAsSb interface. Note that the type II PL from GaAsSb/InP interface has already been observed and analyzed. ${ }^{11,18}$ The PL measurements were carried out using an Ar laser as a light source. The samples are placed in a closed cycle He cryostat with a stable temperature of $10 \mathrm{~K}$. The PL emission is dispersed through a JobinYvon model HR-640 spectrometer and detected using nitrogen cooled InSb photodiode. Figure 2(a) shows the PL spectra at four different optical excitation power $(400 \mathrm{~mW}, 40$ $\mathrm{mW}, 4 \mathrm{~mW}$, and $0.4 \mathrm{~mW}$ ). A PL transition is found to emerge in the $0.68 \mathrm{eV}-0.78 \mathrm{eV}$ energy range and attributed to spatially indirect band-to-band recombination of electrons and holes across the InGaAlAs/GaAsSb interface. At $4 \mathrm{~mW}$ optical excitation power, the PL peak is centered at $0.703 \mathrm{eV}$. By increasing the power by a factor of 100 , the PL peak shifts towards high energy by $30 \mathrm{meV}$. The significant

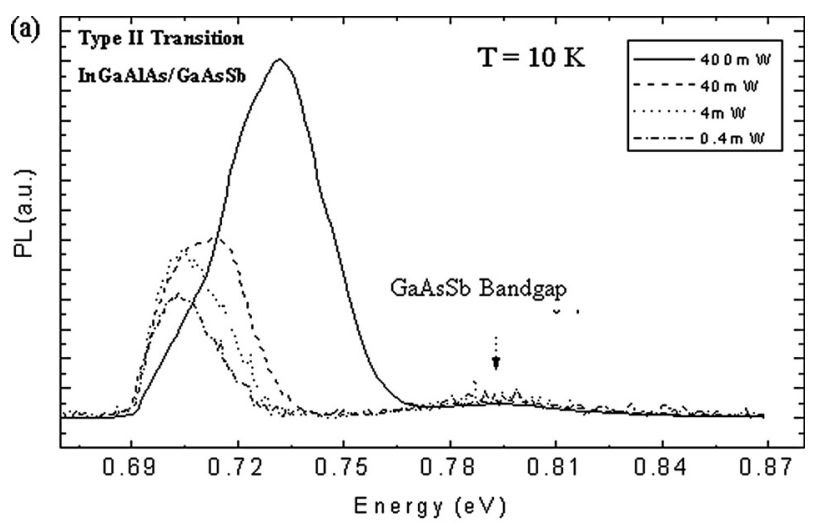

(b)

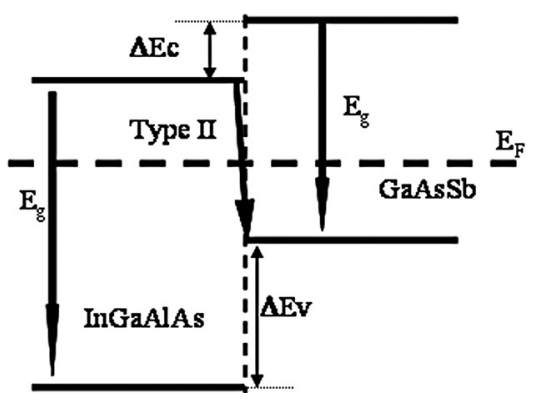

FIG. 2. (a) PL spectra of sample A taken as a function of excitation power. (b) Schematic of the InGaAlAs/GaAsSb (25\% Al, 43\% Sb) type II band structure assuming a flat band conditions. The figure illustrates the band offsets and the gaps/type II transitions. 
blueshift of the PL peak with increasing excitation power is attributed to the band bending effect due to the spatial separation of electrons and holes at the InGaAlAs/GaAsSb interface, and this is a signature for a type II interface recombination. ${ }^{11,18}$ The significant blueshift is understood as follows: Because electrons and holes are attracted to each other, narrow triangular shaped quantum wells (QW) are formed at the interface. When the optical power increases, carriers are accumulated in the QW increasing the confinement energy of the wells as well as the dipole energy across the interface. Additionally, the atypical and asymmetrical shape of the PL spectra especially at high power (Figure 2(a)) is another signature of the type II transition. Specifically, the laser spot size on sample A is $\sim 0.3 \mathrm{~mm}$ in which the power is not uniformly distributed. Since the type II transition energy is highly sensitive to excitation power as described above, the observed PL spectra are the sums of multiple blue-shifted Gaussians, whose origins are the multiple triangular shaped QW caused by the non-uniform macro spot. This leads to multiple peaks like and an asymmetrical shaped spectrum. Furthermore, from the energy of the type II transition, the conduction band offset $\Delta \mathrm{E}_{\mathrm{C}}$ at the InGaA$1 \mathrm{As} / \mathrm{GaAsSb}$ interface can be determined. At low PL excitation power $(0.4 \mathrm{~mW}-4 \mathrm{~mW})$, no significant energy shift is noticed, so it is seemingly assumed that flat band conditions have occurred. As a result, the difference between the GaAsSb bandgap $(0.813 \mathrm{eV})$ at low temperature and the lowest power density type II interface recombination $(0.703 \mathrm{eV})$ energy yields to an estimation of the conduction band offset at the InGaAlAs/GaAsSb interface which is about $(110 \pm 5)$ $\mathrm{meV}$ in this case. Figure 2(b) illustrates the schematic of the InGaAlAs/GaAsSb band structure in a flat band conditions. Similarly, the valence band offset at the InGaAlAs/GaAsSb interface can be determined as the difference between the lowest InGaAlAs transition $(1.096 \mathrm{eV})$ and the type II energy $(0.703 \mathrm{eV})$. This leads to $\Delta \mathrm{E}_{\mathrm{V}}=(393 \pm 19) \mathrm{meV}$. Based on our current and previous experimental results on InGaAlAs/ $\mathrm{GaAsSb}$ and $\mathrm{InP} / \mathrm{GaAsSb}$ (Ref. 12) heterostructures, and for approximately a similar $\mathrm{Sb}$ content, InP shows a lower negative conduction band offset than that of InGaAlAs.

Now that the InGaAlAs/GaAsSb interface nature is identified and characterized using a simple structure, the HBT optical results can be analyzed. The HBT device sam-

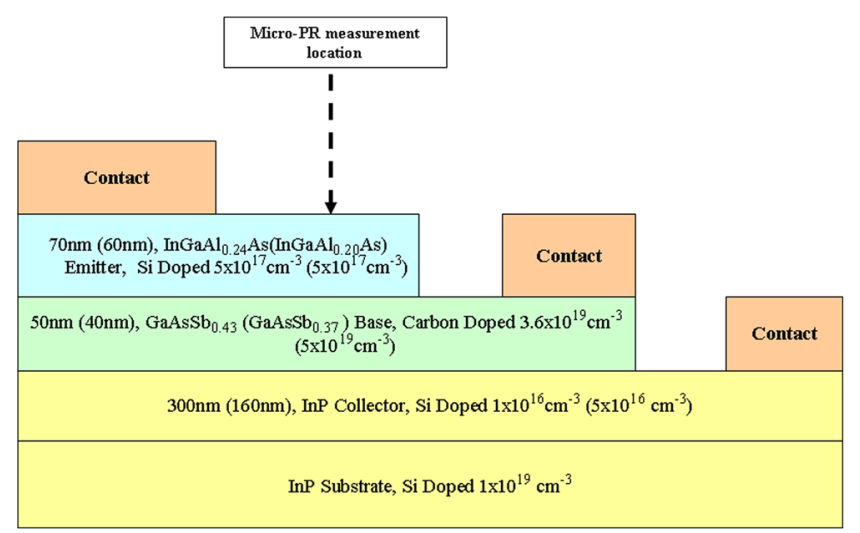

FIG. 3. Side view of the HBT structure of sample B (C). Values in brackets belongs to sample $\mathrm{C}$. A dashed arrow is pointing to the position of the micro-PR measurement spot. ples used in our experiments were grown by MBE on the InP substrate. The structures are summarized in Figure 3. Samples have different collector thicknesses and base antimony contents (43\% for sample B and 37\% for sample C) as well as different emitter $\mathrm{Al}$ contents (24\% for sample B and $20 \%$ for sample C). As both samples are structurally distinct, it is obvious to expect different device performances. The microPR experimental apparatus description is detailed in Ref. 19. Corresponding spatial resolution is estimated to be $7 \mu \mathrm{m}$. Figure 4 shows the micro-PR spectrum of sample $B$ at $300 \mathrm{~K}$. The structure around $1 \mathrm{eV}$ corresponds to the $\mathrm{n}$ InGaAlAs emitter layer, while that around $1.34 \mathrm{eV}$ is related to the $\mathrm{n}$-InP collector layer. The oscillators features above the band gaps of the InGaAlAs $(1.042 \mathrm{eV})$ and $\operatorname{InP}(1.34 \mathrm{eV})$ are the Franz-Keldysh oscillations (FKO). Measured electric fields from the $\mathrm{E} / \mathrm{B}$ and $\mathrm{B} / \mathrm{C}$ are, respectively, $(75 \pm 4) \mathrm{kV} /$ $\mathrm{cm}$ and $(25 \pm 2) \mathrm{kV} / \mathrm{cm}$. These field values were interpreted and compared with numerical simulations based on the Poisson equation. ${ }^{19}$ The FKO spectra have indicated significantly lower donor doping concentration than the nominal target one in the emitter regions, a result later confirmed by the measurement of the net doping concentration using micro$\mathrm{PR}$ as a function of applied bias voltage. ${ }^{19}$ However, several HBT devices like sample $\mathrm{C}$ draw our attention to an unusual and distinctive behavior. Figure 5 shows the room temperature PR spectrum of sample C. FKO related to the InGaAlAs emitter were not observed while the signal related the InP collector exhibits much stronger FKO in terms of amplitude and electric field than that of the sample B. This PR intensity enhancement in the collector is attributed to the thinner InP layer and its higher doping concentration. The measured field is $(72 \pm 4) \mathrm{kV} / \mathrm{cm}$, in perfect agreement with the simulated numerical value. As regards the $\mathrm{E} / \mathrm{B}$ interface, there seems to be no electric field modulation, caused by the deficiency of the photovoltage effect. The photovoltage effect is described as the change of the interface potential induced by photogenerated carriers. The photovoltage effect is the origin of the PR signal. As described above, the InGaAlAs/GaAsSb interface is of type II where carriers crossed recombinations are dominant as can be observed from the PL spectra shown in Figure 2(a) and the band structure in Figure 2(b). This

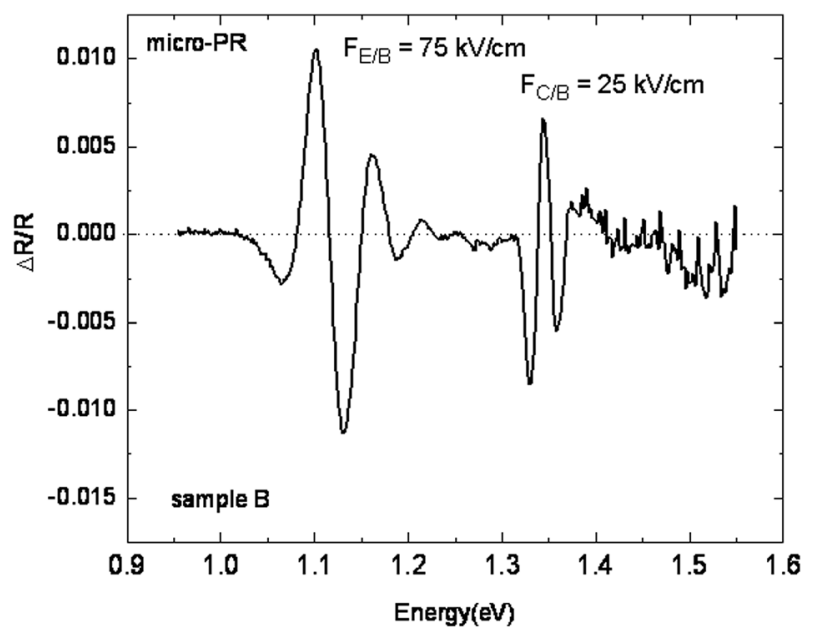

FIG. 4. Room temperature $\mathrm{PR}$ spectrum of the InGaAlAs/GaAsSb/InP HBT, sample B. 


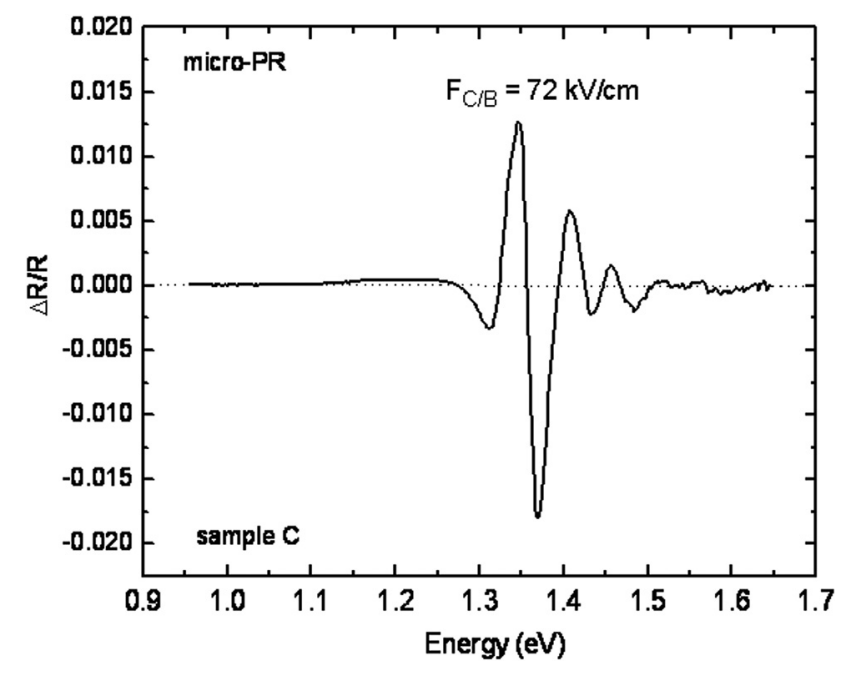

FIG. 5. Room temperature PR spectrum of the InGaAlAs/GaAsSb/InP HBT, sample C.

type II interface effect behaves as defects and nonradiative recombination centers reducing the photovoltage which may explain the lack of PR signal in case of sample $\mathrm{C}$ where the composition in $\mathrm{Al}$ is $20 \%$, while for sample B is $24 \%$. Based on our own observations, the less $\mathrm{Al}$ composition in the quaternary InGaAlAs should correspond to higher conduction band offset discontinuity with GaAsSb. As a result, crossed recombinations due to the type II heterojunction in sample $\mathrm{C}$ $(20 \% \mathrm{Al})$ are stronger than that of sample B $(24 \% \mathrm{Al})$ which explains the lack of FKO at the emitter of sample C. The current voltage characteristics of the E/B heterojunctions for samples $\mathrm{B}$ and $\mathrm{C}$ are also investigated. Extracted from the Gummel plots, ${ }^{20}$ the ideality factor of sample B is 1.035 whereas that of sample C-where the FKO are totally absent-is nearly 2. No FKO behavior was detected on all samples with Gummel ideality factor of 2 . These electrical characteristics confirm our assumptions described above that the recombination currents across the $\mathrm{E} / \mathrm{B}$ heterojunctions on sample $\mathrm{C}$ are stronger than that of sample $\mathrm{B}$. The increase of the ideality factor indicates that the various recombination currents in the $\mathrm{E} / \mathrm{B}$ space charge region-including the crossed recombination current due to the type II interface-increases, which leads to the degradation of the HBT performance.

In conclusion, based on PL spectroscopy experiments, the InGaAlAs/GasAsSb interface appears to be of type II for $\mathrm{Al}$ concentration between $20 \%$ and $25 \%$. This results in carriers crossed recombination through the InGaAlAs/GaAsSb interface. On the other hand, micro-PR performed on real InGaAlAs/GasAsSb/InP HBT micro-devices show typical behavior coming from the InP collector. Whereas for some devices, FKO in the vicinity of the InGaAlAs (emitter) band gap energy were not observed. This behavior is attributed to the type II interface effect which behaves as defects and nonradiative recombination centers reducing the pump beam modulation efficiency. A correlation of practical significance between PR results and Gummel characteristics is recorded. An ideality factor $\sim 2$ is seen on all samples where the PR response is absent. The ideality factor increase is a signature of the various recombination currents in the $\mathrm{E} / \mathrm{B}$ space charge region which optically leads to the lack of the FKO.

This work was supported by the French National Network of Research in Telecommunications (RNRT), MELBA project. The authors would like to thank Dr. P. Bove (Picogiga International) and Dr. M. Lijadi, and Dr. J.-L. Pelouard (LPN).

${ }^{1}$ H. Nakajima, K. Kurishima, S. Yamahata, T. Kobayashi, and Y. Matsuoka, IEICE Trans. Electron E78C, 1171 (1995). Available at: http:// search.ieice.org/bin/summary.php?id=e78-c_9_1171.

${ }^{2}$ M. Ida, K. Kurishima, and N. Watanabe, IEEE Electron Device Lett. 23, 694 (2002).

${ }^{3}$ M. Dahlstrom, X.-M. Fang, D. Lubyshev, M. Urteaga, S. Krishnan, N. Parthasarathy, Y. M. Kim, Y. Wu, J. M. Fastenau, W. K. Liu, and M. J. W. Rodwell, IEEE Electron Device Lett. 24, 433 (2003).

${ }^{4}$ J. Godin, M. Riet, A. Konczykowska, P. Berdaguer, M. Kahn, P. Bove, H. Lahreche, R. Langer, M. Lijadi, F. Pardo, N. Bardou, J.-L. Pelouard, C. Maneux, M. Belhaj, B. Grandchamp, N. Labat, A. Touboul, C. Bru-Chevallier, H. Chouaib, and T. Benyattou, in 13th European Gallium Arsenide and Other Semiconductor Application Symposium, EGAAS 2005 (IEEE, 2005), p. 133.

${ }^{5}$ A. Konczykowska, M. Riet, P. Berdaguer, P. Bove, M. Kahn, and J. Godin, Electron. Lett. 41, 905 (2005).

${ }^{6} \mathrm{M}$. W. Dvorak, C. R. Bolognesi, O. J. Pitts, and S. P. Watkins, IEEE Electron Device Lett. 22, 361 (2001).

${ }^{7}$ H. Maher, V. Delmouly, U. Rouchy, M. Renvoise, P. Frijlink, D. Smith, M. Zaknoune, D. Ducatteau, V. Avramovic, A. Scavennec, J. Godin, M. Riet, C. Maneux, and B. Ardouin, in 23rd Conference on IPRM, 22-26 May 2011.

${ }^{8} \mathrm{P}$. Bove, H. Lahreche, and R. Langer, in 14th Conference on IPRM (IEEE 2002), p. 607.

${ }^{9}$ F. H. Pollak, Handbook on Semiconductors, edited by M. Balkanski (North Holland, New York, 1994), Vol. 2, p. 554.

${ }^{10}$ J. Misiewicz, P. Sitarek, G. Sęk, and R. Kudrawiec, Mater. Sci. 21, No, 3 (2003).

${ }^{11}$ H. Chouaib, C. Bru-Chevallier, G Guillot, H. Lahreche, and P. Bove, J. Appl. Phys. 98, 123524 (2005).

${ }^{12}$ C. Bru-Chevallier, H. Chouaib, J. Arcamone, T. Benyattou, H. Lahreche, and P. Bove, Thin Solid Films 450, 151 (2004).

${ }^{13}$ H. Chouaib, C. Bru-Chevallier, A. Apostoluk, W. Rudno-Rudzinski, M. Lijadi, and P. Bove, Appl. Phys. Lett. 93, 041913 (2008).

${ }^{14}$ H. Takeuchi, Y. Yamamoto, and N. Nakayama, J. Appl. Phys. 96, 1967 (2004).

${ }^{15}$ Y. Yan, F. H. Pollak, V. T. Boccio, C. L. Lin, P. D. Kirchner, and J. M. Woodall, Appl. Phys. Lett. 61, 2066 (1992).

${ }^{16}$ D. E. Aspnes, Surf. Sci. 37, 418 (1973).

${ }^{17}$ P. Estrera, W. M. Duncan, and R. Glosser, Phys. Rev. B. 49, 7281 (1994).

${ }^{18}$ M. Peter, N. Herres, F. Fuchs, K. Winkler, K.-H. Bachem, and J. Wagner, Appl. Phys. Lett. 74, 410 (1999).

${ }^{19}$ H. Chouaib and C. Bru-Chevallier, Appl. Phys. Lett. 90, 262102 (2007).

${ }^{20}$ M. Lijadi, Ph.D. dissertation, Université Paris VI, Pierre Et Marie Curie, 2005. 